\title{
Motor vehicle and fall related deaths among older Americans 1990-98: sex, race, and ethnic disparities
}

\author{
J A Stevens, A M Dellinger
}

Injury Prevention 2002;8:272-275

\begin{abstract}
See end of article for authors' affiliations

.........

Correspondence to: Dr Judy A Stevens, National Center for Injury

Prevention and Control,

Centers for Disease Control

and Prevention, 4770

Buford Highway NE,

Mailstop K-63, Atlanta, GA

30341, USA:

jas2@cdc.gov
\end{abstract}

\begin{abstract}
Objectives: To examine differences in motor vehicle and fall related death rates among older adults by sex, race, and ethnicity.

Methods: Annual mortality tapes for 1990-98 provided demographic data including race and ethnicity, date, and cause of death. Trend analyses were conducted using Poisson regression.

Results: From 1990-98, overall motor vehicle related death rates remained stable while death rates from unintentional falls increased. Motor vehicle and fall related death rates were higher among men. Motor vehicle related death rates were higher among people of color while fall related death rates were higher among whites. Among whites, fall death rates increased significantly during the study period, with an annual relative increase of $3.6 \%$ for men and $3.2 \%$ for women.

Conclusions: The risk of death from motor vehicle and fall related injuries among older adults differed by sex, race and ethnicity, results obscured by simple age and sex specific death rates. This study found important patterns and disparities in these death rates by race and ethnicity useful for identifying high risk groups and guiding prevention strategies.
\end{abstract}

A mong people aged 65 and older, motor vehicle crashes and falls are the leading causes of injury deaths. In 1998, 30605 older adults died from unintentional injuries. Of these, $7886(26.8 \%)$ of deaths were due to motor vehicle crashes and 9604 (30.8\%) were due to unintentional falls. ${ }^{1}$ These findings apply to all older adults and do not reflect racial or ethnic disparities found in other studies of health status. For example, researchers have reported that a variety of health problems among people aged 65 and older differ by race and/or ethnicity. Blacks have a higher prevalence of arthritis and hypertension'; black women are more likely than white women to be overweight ${ }^{3}$; blacks and American Indians are more likely than whites or Asians to report they are in fair or poor health. ${ }^{4}$ In general, Hispanics are less likely than non-Hispanics to report a regular source of medical care, and more likely to report delaying medical care due to cost. ${ }^{5}$ Compared with whites, blacks are three times more likely to die in residential fires; ${ }^{6}$ while white women are much more likely than black or Asian women to sustain hip fractures. ${ }^{7}$ However, racial and ethnic differences for other types of injuries have not been well described. The purpose of this report is to describe older adult motor vehicle and fall related death rates by sex, race and ethnicity, and to report differences among population subgroups that are not evident when comparing across broader categories such as age and sex.

\section{METHODS}

Cause of death data for 1990-98 were based on information from death certificates completed by attending physicians, medical examiners or coroners, and coded according to the International Classification of Diseases, ninth revision (ICD-9). ICD-9 includes codes for categorizing the circumstance or external cause of an injury (E code). ${ }^{8}$ The number of unintentional motor vehicle related deaths (codes E810-825) and unintentional fall related deaths (codes E880-886, E888) were obtained from National Center for Health Statistics annual mortality tapes. ${ }^{9}$ These data provided the number of deaths by cause, age group, sex, race, ethnicity, and year of death. Three states did not include ethnicity in their cause of death reporting for one or more years during the study period (Oklahoma 1990-96, New Hampshire 1990-92, and Louisiana 1990-91).
Midyear population estimates for people aged 65 years and older, obtained from census enumerations of the United States Bureau of the Census and intercensal estimates, ${ }^{10}$ were used to calculate death rates for men and women by race (white, black, American Indian/Alaskan Native, Asian/Pacific Islander) and ethnicity (Hispanic, non-Hispanic). The category white includes persons classified as white, Mexican, Puerto Rican, Cuban, and all other Caucasians. Rates based on fewer than 20 deaths in certain sex/race specific categories (which correspond to relative standard errors of $23 \%$ or greater) were considered unstable and not calculated. Rates depicted graphically have been smoothed by using three year moving averages to increase stability, reduce random fluctuations, and clarify trends in the data. ${ }^{11}$ For example, the death rate depicted for 1992 is an average of the data from 1991-93 and the death rate for 1993 is an average of data from 1992-94.

Trend analyses (as the percentage change in annual mortality rates) were conducted using SAS (version 6.09, SAS Institute, Cary, NC) Proc Genmod to perform Poisson regression with a population offset.

\section{RESULTS}

From 1990-98, motor vehicle related death rates for all older adults remained stable while fall related death rates increased (tables 1 and 2). However, these findings apply to all older adults and do not reflect disparities in rates for different racial or ethnic groups.

\section{Motor vehicle related death rates}

Table 1 gives the number of motor vehicle related deaths and death rates for men and women by race and ethnicity annually for the years 1990-98. Figure 1 graphically depicts similar results using three year averaged death rates. Death rates differed by race and ethnicity for men and women. These data show that over the study period, motor vehicle related death rates for men were consistently higher $(79 \%-90 \%)$ than for women; this held true for each race, regardless of Hispanic ethnicity. White and Asian men had the lowest death rates among men, black and American Indian men had the highest. 
Table 1 Number and rates* of motor vehicle deaths by sex, race, $\uparrow$ and ethnicity $\ddagger$ for persons aged 65 years and older, United States, 1990-98§

\begin{tabular}{|c|c|c|c|c|c|c|c|c|c|}
\hline & 1990 & 1991 & 1992 & 1993 & 1994 & 1995 & 1996 & 1997 & 1998 \\
\hline \multicolumn{10}{|l|}{ Men } \\
\hline White & $3566(31.4)$ & $3514(30.4)$ & $3531(30.0)$ & $3606(30.1)$ & $3694(30.4)$ & $3724(30.2)$ & $3876(31.0)$ & $3985(31.6)$ & 4054 (31.9) \\
\hline Black & 349 (36.2) & $348(35.4)$ & $348(34.7)$ & $381(37.3)$ & $390(37.5)$ & $383(36.1)$ & $383(35.5)$ & $354(32.3)$ & $402(36.6)$ \\
\hline \multicolumn{10}{|l|}{ American } \\
\hline Indian & 21 (42.5) & $30(58.2)$ & $25(46.5)$ & $25(44.8)$ & $19(-)$ & $17(-)$ & $27(43.4)$ & $32(49.8)$ & $24(36.2)$ \\
\hline Asian & $68(33.0)$ & $64(29.1)$ & $66(28.1)$ & $52(20.9)$ & $99(37.7)$ & $90(32.5)$ & 69 (23.7) & $93(30.4)$ & $74(22.9)$ \\
\hline Hispanic & $166(34.8)$ & $163(32.1)$ & $145(27.1)$ & $180(31.7)$ & 196 (32.7) & $218(34.4)$ & $235(35.1)$ & $200(28.3)$ & $232(31.3)$ \\
\hline Non-Hispanic & $3626(31.0)$ & $3655(30.3)$ & $3687(30.0)$ & $3757(29.9)$ & $3919(30.8)$ & $3903(30.2)$ & $4023(30.8)$ & $4240(31.7)$ & 4305 (32.0) \\
\hline Total men & 4004 (31.9) & $3956(30.9)$ & $3970(30.4)$ & $4064(30.5)$ & $4202(31.1)$ & $4214(30.7)$ & 4355 (31.3) & $4464(31.7)$ & $4554(32.1)$ \\
\hline \multicolumn{10}{|l|}{ Women } \\
\hline White & $2926(17.4)$ & 2850 (16.7) & $2842(16.5)$ & 2975 (17.0) & $3096(17.6)$ & $3142(17.7)$ & $3106(17.4)$ & $32.3(17.9)$ & $3253(18.1)$ \\
\hline Black & 209 (13.5) & 179 (11.4) & 168 (10.5) & $188(11.6)$ & $224(13.6)$ & $192(11.5)$ & $221(13.1)$ & $243(14.2)$ & 239 (13.8) \\
\hline \multirow{2}{*}{$\begin{array}{l}\text { American } \\
\text { Indian I } \\
\text { Asian }\end{array}$} & & & & & & & & & \\
\hline & $\begin{array}{l}11(-) \\
60(23.7)\end{array}$ & $\begin{array}{c}11(-) \\
47(17.1)\end{array}$ & $\begin{array}{l}13(-) \\
60(20.1)\end{array}$ & $\begin{array}{l}16(-) \\
78(24.2)\end{array}$ & $\begin{array}{l}15(-) \\
65(18.8)\end{array}$ & $\begin{aligned} 8 & (-) \\
70 & (18.9)\end{aligned}$ & $\begin{array}{l}18(-) \\
84(21.3)\end{array}$ & $\begin{array}{l}31(35.5) \\
86(20.6)\end{array}$ & $\begin{array}{l}25(27.7) \\
74(16.7)\end{array}$ \\
\hline Hispanic & 99 (14.7) & 98 (13.7) & 107 (14.2) & 114 (14.3) & $113(13.5)$ & 121 (13.7) & $128(13.8)$ & $136(14.0)$ & 114 (11.2) \\
\hline Non-Hispanic & 2939 (16.9) & 2878 (16.1) & 2890 (15.9) & $3037(16.5)$ & 3224 (17.3) & $3223(17.2)$ & 3213 (17.1) & 3419 (17.9) & 3468 (18.1) \\
\hline Total women & $3206(17.2)$ & $3087(16.3)$ & $3083(16.0)$ & $3257(16.7)$ & 3400 (17.3) & 3412 (17.2) & 3429 (17.1) & $3563(17.7)$ & 3591 (17.8) \\
\hline Grand total & $7210(23.1)$ & $7044(22.2)$ & $7053(21.8)$ & $7321(22.3)$ & 7602 (22.9) & 7626 (22.7) & 7784 (22.9) & $8027(23.5)$ & 8145 (23.7) \\
\hline $\begin{array}{l}\text { * Rates calculated } \\
\text { tRace category of } \\
\text { tHispanic and non } \\
\text { category. } \\
\text { \$Reports on Hispar } \\
\text { \Most rates for Am }\end{array}$ & $\begin{array}{l}\text { gin exc } \\
\text { Indian }\end{array}$ & 5 & tive; & . & can be in & der. & aory and & the Hispan & on-Hispanic \\
\hline
\end{tabular}

Table 2 Number and rates* of unintentional fall deaths by sex, race, $\uparrow$ and ethnicity $\ddagger$ for persons aged 65 years and older, United States, 1990-98§

\begin{tabular}{|c|c|c|c|c|c|c|c|c|c|}
\hline & 1990 & 1991 & 1992 & 1993 & 1994 & 1995 & 1996 & 1997 & 1998 \\
\hline \multicolumn{10}{|l|}{ Men } \\
\hline White & $76(24.5)$ & $903(25.1)$ & 721 (24.8) & $3020(25.2)$ & 3244 (26.7) & $3296(26.7)$ & $3649(29.2)$ & $3965(31.5)$ & 4099 (32.3) \\
\hline Black & $172(17.9)$ & 170 (17.3) & 170 (17.0) & 190 (18.6) & 165 (15.9) & 196 (18.5) & 180 (16.7) & 190 (17.3) & $194(17.4)$ \\
\hline Americ & & & & & & & & & \\
\hline $\begin{array}{l}\text { Indiar } \\
\text { Asian }\end{array}$ & $\begin{array}{l}12(-) \\
49(23.8)\end{array}$ & $\begin{array}{l}13(-) \\
28(12.7)\end{array}$ & $\begin{aligned} 9 & (-) \\
50 & (21.3)\end{aligned}$ & $\begin{array}{l}18(-) \\
39(15.7)\end{array}$ & $\begin{array}{l}10(-) \\
70(26.7)\end{array}$ & $\begin{array}{l}13(-) \\
66(23.9)\end{array}$ & $\begin{aligned} 3 & (-) \\
63 & (21.7)\end{aligned}$ & $\begin{array}{l}21(32.7) \\
64(20.9)\end{array}$ & $\begin{array}{l}12(-) \\
76(23.5)\end{array}$ \\
\hline Hisp & (19.1) & 84 (16.5) & $112(209)$ & 102 (18.0) & 110 (18.3) & 142 (22.4) & ) & 1) & 1) \\
\hline Non-Hispanic & $2783(23.8)$ & $2936(24.3)$ & 2951 (24.0) & $3074(24.5)$ & 3339 (26.2) & $3366(26.1)$ & $3681(28.2)$ & $4084(30.6)$ & $4206(31.3)$ \\
\hline Total men & $3009(24.0)$ & 4.3) & $150(24.1)$ & $3267(24.6)$ & 3489 & 3571 & $3895(28.0)$ & $4240(30.1)$ & $4381(30.9)$ \\
\hline \multicolumn{10}{|l|}{ Wom } \\
\hline Wh & 1) & ) & & & & & & & 494 \\
\hline Black & 167 & 17 & 1 & 157 & 145 & 173 & 170 & 1.3) & 198 (11.4) \\
\hline American & & & & & & & & & \\
\hline Asian & $26(10.3)$ & $21(7.6)$ & 39 (13.1) & 35 (10.9) & $34(9.8)$ & 43 (1 11.6$)$ & 49 (12.4) & 62 (14.8) & 60 (13.5) \\
\hline & & & & & & & & & \\
\hline Non-Hispanic & 33361 & 3586 & 360 & 36 & 374 & 3969 & 435 & $46 c$ & 5063 \\
\hline Total women & 3591 (19.2) & $3805(20.1)$ & $3811(19.8)$ & $3863(19.8)$ & 3881 (19.7) & $4150(20.9)$ & $4579(22.9)$ & $4783(23.8)$ & $5223(25.9)$ \\
\hline Grand total & $6601(21.1)$ & $6922(21.8)$ & 961 (21.6) & $7130(21.7)$ & 7370 (22.2) & 7721 (23.0) & $8474(25.0)$ & $9023(26.4)$ & $9604(27.9)$ \\
\hline
\end{tabular}

*Rates calculated per 100000 age specific population.

†Race category of American Indian includes Alaskan Native; race category of Asian includes Pacific Islander.

fHispanic and non-Hispanic ethnicity is used separately from the race category. A person can be included in one race category and either the Hispanic or non-Hispanic category.

§Reports on Hispanic origin exclude data from the following states: Oklahoma 1990-96, New Hampshire 1990-92, Louisiana 1990-91.

『Rates for American Indians/Alaskan Natives, and Asian men in 1991, were not calculated due to instability of rates based on fewer than 20 deaths.

The results for women differed. Black women had the lowest motor vehicle related death rates, Asian women the highest. Hispanic women always had lower rates than nonHispanic women. For seven of the nine study years, annual death rates for American Indian women were not calculated due to small numbers of deaths. Using three year averaged rates, American Indian women had some of the highest and lowest rates. The small sample sizes, even using three year averaged rates, continued to generate rates with the greatest variability among the races (fig 1 ).

The differences between men and women tended to be larger than sex specific differences by race or ethnicity (fig l). 

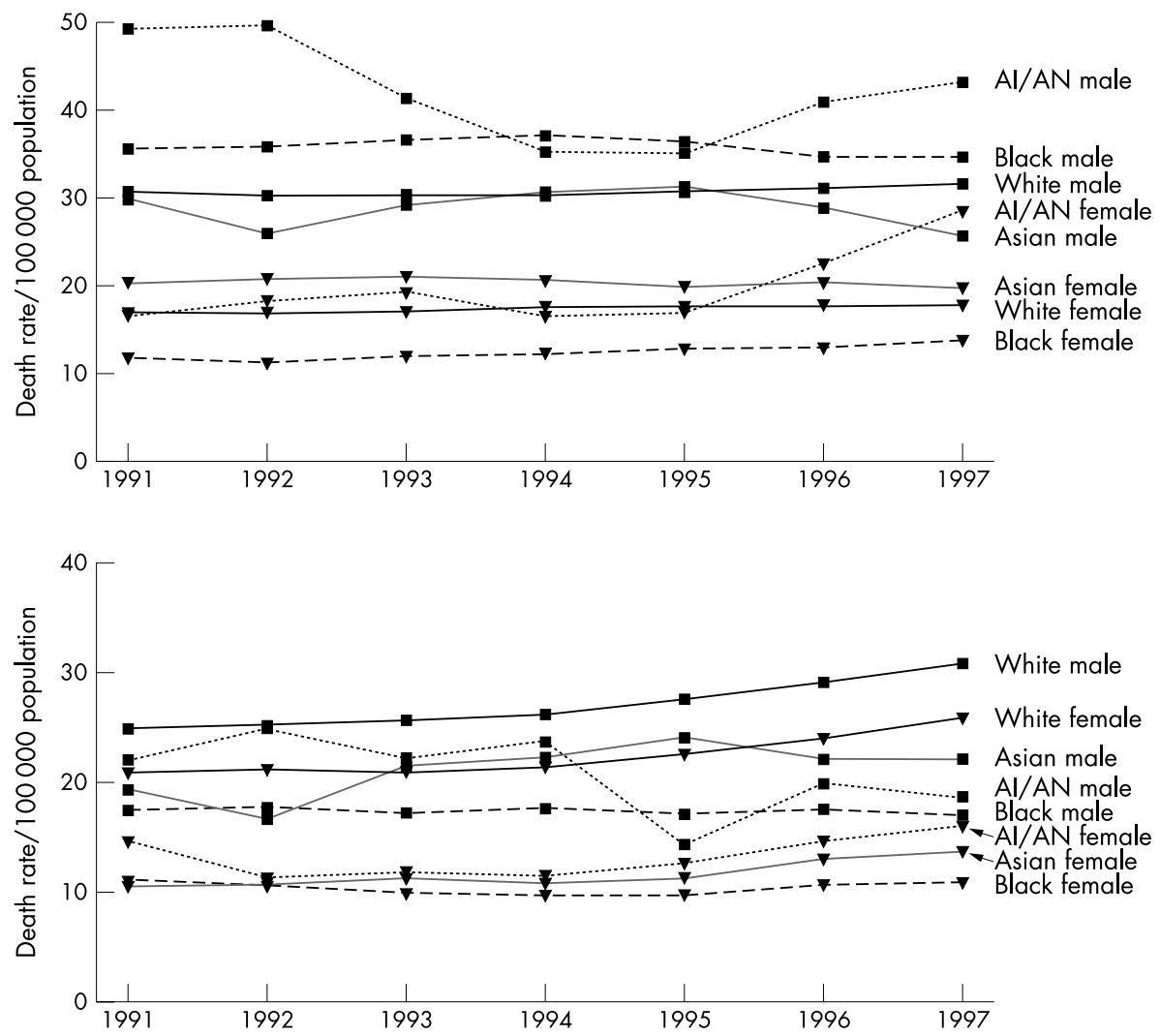

Figure 1 Three year averaged* unintentional motor vehicle related death rates for persons aged 65 and older by race and sex, United States (Al/AN, American Indian/Alaskan Native). *Three year averaged death rates calculated by averaging 1990-92 for the 1991 rate, 1991-93 for the 1992 rate etc.
Figure 2 Three year averaged* unintentional fall related death rates for persons aged 65 and older by race and sex, United States $(\mathrm{Al} / \mathrm{AN}$, American Indian/Alaskan Native). * Three year averaged death rates calculated by averaging 1990-92 for the 1991 rate, $1991-93$ for the 1992 rate etc.
For example, in 1998 the death rate for Hispanic men was nearly three times the rate of Hispanic women $(31.3 v 11.2$ respectively) whereas the death rate for white women was 1.3 times the rate of black women and 1.6 times the rate of Hispanic women (18.1, 13.8, and 11.2 respectively).

\section{Fall death rates}

Table 2 provides the number of fall related deaths and death rates for 1990-98 for men and women aged 65 years and older, by race and ethnicity. Figure 2 shows the results graphically by sex and race using three year averaged death rates. Fall rates differed by race and sex. Among men, rates were consistently higher among whites and non-Hispanics. In 1998, the rate for white men was almost 1.9 times the rate for black men and 1.4 times the rate for Asian men.

Fall death rates among women also differed by race. Throughout the study period, fall death rates for white women were approximately twice those for women of other races. While the 1998 rate for white women was only $17 \%$ lower than the rate for white men, it was 2.4 times the rate for black women and 2.0 times the rate for Asian women. Similarly, the 1998 death rate for non-Hispanic women was 1.9 times the rate for Hispanic women. The annual relative increase in fall death rates for whites was $3.8 \%$ for both men and women $(\mathrm{p}<0.01$, test for linear trend). By 1998, the rate for whites overall (29.5) was twice the rate for all other races combined (14.7) $(\mathrm{p}<0.01)$.

\section{DISCUSSION}

In the United States, more than half of all unintentional injury deaths among people aged 65 years and older (greater than 16000 deaths each year) are caused by motor vehicle crashes and unintentional falls. Our study found that from 1990-98 motor vehicle related deaths remained stable for both sexes and most racial groups, while fall related death rates increased. Important racial and ethnic differences were identified for men and women. For example, motor vehicle related death rates for men were highest among American Indians and blacks. Death rates for women were highest among American Indians and Asians and lowest among blacks. Older Asian women had motor vehicle related death rates nearly twice those of black women. Fall related death rates for both men and women were highest among whites. Rates were lowest among blacks and about half the rate of whites. Non-Hispanics consistently had higher fall related death rates than Hispanics with average annual increases among white and non-Hispanic men and women of $2 \%$ to $4 \%$.

A limitation of this study is potential misclassification of the decedent by either race or ethnicity. Race data from differing data sources (death certificates, National Mortality Follow-back Survey, Current Population Surveys) are highly consistent for whites and blacks, less so for Asians and Hispanics, and even less so for American Indians. ${ }^{12-15}$ A study comparing death certificates to other sources found $40 \%$ under-reporting for American Indians, 13\% for Asians, and 7\% for Hispanics. ${ }^{15}$ Moreover, there is a documented tendency to misclassify American Indians and Asians as white. ${ }^{16}$ This type of misclassification would tend to underestimate the death rates for these groups and increase the rate variability caused by small numbers. Also, three states did not include ethnicity in their cause of death reporting for one or more years during the study period (Oklahoma 1990-96, New Hampshire 199092, Louisiana 1990-91). Because this would represent very few deaths, it is unlikely that these omissions affected our results. We report national and not state or regional rates. Although information about geographic variations would be helpful for public health practitioners, we chose to describe national rates because these provided the most stable estimates. Lastly, the motor vehicle related death rates were not adjusted for exposure or the amount of annual travel. It may be that travel among older adults differs by race and/or ethnicity. If this is the case, and some groups travel less than others, their rates may be underestimated.

The strengths of this study include using a smoothing technique (calculating three year averaged death rates) that 


\section{Key points}

- The risk of death differed by race and ethnicity

- From 1990-98, overall motor vehicle related death rates remained stable.

- From 1990-98, death rates from unintentional falls increased significantly.

- Motor vehicle and fall related death rates were higher among men.

- Motor vehicle related death rates were higher among people of color.

- Fall related death rates were higher among whites.

enabled racial groups with small numbers of deaths (for example, American Indians, Asians) to be included in most of the comparisons. This is an improvement over the more common reporting scheme of "white, black, and other". Our results indicate that this "other" category was quite heterogeneous. Also, these subgroup analyses revealed what overall fall related death rates for men and women did not reveal: the increasing death rates among whites and non-Hispanics.

Because older adults are the fastest growing segment of our population, reducing motor vehicle crashes and falls among older adults offers an opportunity to improve the public's health. This is particularly important because older adults are more vulnerable to injury given their general level of physical frailty. In motor vehicle crashes of similar severity, a person aged 70 years is about three times more likely to die than a person aged 20. ${ }^{17}$ Among people aged 65 years and older, motor vehicle and fall related mortality together account for $60 \%$ of all unintentional injury deaths. However, the greatest impact of these injuries is on morbidity, chronic disability, and decreased quality of life. Motor vehicle crashes among older adults cause more than 200000 non-fatal injuries each year and these numbers are rising. ${ }^{2}$ From 1990 through 1997, the number of non-fatal motor vehicle related injuries to persons age 65 and older increased $19 \%{ }^{18}$ Falls are the second leading cause of head and spinal cord injury in the elderly, ${ }^{19}$ and hip fractures, $95 \%$ of which are due to falls, ${ }^{20}$ result in more than 300000 hospitalizations annually. ${ }^{21}$

To effectively reduce the substantial mortality and morbidity from motor vehicle crashes and falls, injury interventions for older adults need to focus on specific high risk groups. The mortality data reported here can be used to identify these high risk groups. However, fatal injuries represent only a small portion of the overall injury burden. The next steps are to identify those older adults at highest risk for non-fatal motor vehicle and fall related injuries, and to use these data to inform public health policy and prevention strategies.

\section{ACKNOWLEDGEMENTS}

The authors would like to acknowledge Dr Christine Branche, Dr David Sleet, Ms Sarah Olson, and Dr Bruce Jones for their thoughtful comments and suggestions, and Ms Marcie-Jo Kresnow Sedacca for her statistical assistance.

\section{Authors' affiliations}

J A Stevens, A M Dellinger, National Center for Injury Prevention and Control, Centers for Disease Control and Prevention, Atlanta, Georgia, USA

\section{REFERENCES}

1 Murphy SL. Deaths: final data for 1998. National vital statistics reports Vol 48, No 11. Hyattsville, MD: National Center for Health Statistics, 2000

2 Centers for Disease Control and Prevention. Surveillance for morbidity and mortality among older adults-United States, 1995-1996. In: Surveillance for selected public health indicators affecting older adults - United States. MMWR Morb Mortal Wkly Rep 1999;48(SS-8):7-25.

3 Centers for Disease Control and Prevention. Surveillance for five health risks among older Adults - United States, 1993-1997. In Surveillance for selected public health indicators affecting older adults-United States. MMWR Morb Mortal Wkly Rep 1999;48(SS-8):89-130.

4 Centers for Disease Control and Prevention. Surveillance for sensory impairment, activity limitation, and health-related quality of life among older adults-United States, 1993-1997. In: Surveillance for selected public health indicators affecting older adults-United States. MMWR Morb Mortal Wkly Rep 1999;48(SS-8): 131-56.

5 Centers for Disease Control and Prevention. Surveillance for use of preventive health-care services by older adults, 1995-1997. In: Surveillance for selected public health indicators affecting older adults-United States. MMWR Morb Mortal Wkly Rep 1999;48(SS-8):51-88

6 Federal Emergency Management Agency, United States Fire Administration, National Fire Data Center. Fire in the United States, 1987-1996. 11th Ed. Emmitsburg, MD: United States Fire Administration, Federal Emergency Management Agency, 1999.

7 Ellis AA, Trent RB. Hospitalized fall injuries and race in California. Inj Prev 2001;7:316-20.

8 World Health Organization. International classification of diseases, ninth revision, clinical modification. Second printing. Ann Arbor, Ml: Commission on Professional and Hospital Activities, March 1980.

9 National Center for Health Statistics. Vital statistics of the United States, mortality, underlying and multiple causes of death, public use files. Hyattsville, MD: NCHS (annual).

10 US Bureau of the Census. Population Estimates Branch, Population Division, Washington, DC, 1998

11 Vogt WP. Dictionary of statistics and methodology. Newbury Park, CA: Sage Publications, 1993

12 Frost F, Tollestrup K, Ross A, et al. Correctness of racial coding of American Indians and Alaska Natives on the Washington state death certificate. Am J Prev Med 1994; 10:290-4

13 Kelly JJ, Chu SO, Diaz T, et al. Race/ethnicity misclassification of persons reported with AIDS. Ethnicity and Health 1996;1:87-94.

14 National Center for Health Statistics. Comparability of the death certificate and the 1986 National Mortality Followback Survey. Series 2:
Data evaluation and methods research, No 118 . Hyattsville, MD: NCHS. Data evaluation and methods research, No 118. Hyattsvill
DHHS Publication No (PHS)94-1392; November, 1993.

15 Rosenberg HM, Maurer JD, Sorlie PD, et al. Quality of death rates by race and Hispanic origin: a summary of current research, 1999 National Center for Health Statistics. Vital Health Stat 1999;2(128).

16 Sortie PD, Rogot E, Johnson NJ. Validity of demographic characteristics on the death certificate. Epidemiology 1992;3:181-4.

17 Evans L. Risk of fatality from physical trauma versus sex and age. $J$ Trauma 1988;28:368-78.

18 Centers for Disease Control and Prevention. Surveillance for Injuries and Violence Among Older Adults. In: Surveillance for Selected Public Health Indicators Affecting Older AdultsBUnited States. MMWR Morb Mortal Wkly Rep 1999:48(SS-8):27-50.

19 Kraus KF, Black MA, Hessol N, et al. The incidence of acute brain injury and serious impairment in a defined population. Am J Epidemiol 1984;119:186-201.

20 Nyberg L, Gustafson $Y$, Berggren D, et al. Falls leading to femoral neck fractures in lucid older people. J Am Geriatr Soc 1996;44:156-60.

21 Lawrence L, Hall M. 1997 Summary: national hospital discharge survey. Advance Data from Vital and Health Statistics; No 308. Hyattsville, MD: National Center for Health Statistics, 1999. 